\title{
Pointer
}

\section{The application of prophylactic antibodies for rhinovirus infections}

\author{
Riccardo Privolizzi', Roberto Solari², Sebastian L Johnston², Gary R McLean ${ }^{2,3 *}$ \\ ${ }^{1}$ School of Human Sciences, London Metropolitan University, London, UK \\ ${ }^{2}$ Airway Disease Infection Section, National Heart and Lung Institute, Imperial College London, London, UK \\ ${ }^{3}$ Cellular and Molecular Immunology Research Centre, London Metropolitan University, London, UK \\ ${ }^{*}$ Corresponding author e-mail: g.mclean@imperial.ac.uk
}

Rhinoviruses are extremely common pathogens of the upper respiratory tract with adults experiencing on average 2-5 infections per year and children up to 12 infections. Although infections are not life threatening, except in cases of chronic lung disease where rhinoviruses are the major precipitant of acute exacerbations of disease, there is a high associated economic cost resulting from lost productivity due to absence from work or school. Treatment of infections focuses on symptom relief with anti-pyretics/analgesics as there are no antiviral therapies available and vaccine strategies face difficulties because of the large number of viral serotypes. Here, we assess the potential for prophylactic antibody intervention for these ubiquitous human pathogens.

\section{Therapeutic/prophylactic antibodies}

Antibodies (Abs) are glycoproteins of the immunoglobulin superfamily that are produced by B-lymphocytes to foreign antigens (for review see [1]). During immune responses Abs are produced in a polyclonal fashion to antigens, although individual B-cells produce a single Ab clonotype. Importantly, in 1975 the advent of hybridoma technology permitted the isolation of B-cell clones allowing for continued production of monoclonal Abs [2]. Over the last 30 years, exploitation of their ability to specifically recognise, immobilize, destroy or clear such antigens has seen Abs transformed from diagnostic markers and laboratory tools into powerful therapeutics and prophylactics for human diseases. These Abs are usually of the immunoglobulin ( $\mathrm{Ig}) \mathrm{G}$ isotype due to their relatively long half-life and superior effector function as opposed to that of the $\operatorname{IgA}$ and $\operatorname{IgM}$ isotypes, which have more specialized functions. Approximately 30 monoclonal Abs are currently licensed for use to treat human diseases such as cancer, autoimmune disorders, allergy and transplant rejection [3]. Although the adaptive immune response and therefore Abs evolved to protect jawed vertebrates against infectious disease pathogens [4], to date just one monoclonal $\mathrm{Ab}$ (palivizumab or Synagis ${ }^{\mathrm{TM}}$ ) is licensed that targets an infectious disease pathogen (respiratory syncytial virus). Nevertheless, several Abs (approximately 10 of 200) are undergoing preclinical development or are in clinical trials for viral infectious diseases targets including HIV-1, HBV, human rhinoviruses (RV) and human cytomegalovirus [3]. RV may be particularly suited to the application of prophylactic Abs as no appropriate antiviral therapies are available despite numerous attempts [5-7], vaccine development faces challenging obstacles [8,9] and new information regarding protective antibody responses is being unearthed [10-14]. Thus, a full evaluation of the application of prophylactic Abs to these important human pathogens where there is an explicit need for appropriate therapeuticl prophylactic interventions is warranted.

\section{Rhinoviruses and human disease}

RVs are human pathogens of the respiratory tract being the most frequent cause of mild diseases of the upper respiratory tract (common cold) and the major trigger of acute exacerbations of chronic airway diseases $[15,16]$. In part, the success of RVs as human pathogens is due to the existence of numerous antigenically distinct serotypes and their associated heterogeneity. Serotypes were originally numbered 1 to 100 based on $\mathrm{Ab}$ neutralization properties with polyclonal antisera [17-19] and RVs can also be divided into three clusters (RV types A, B and C) based on sequence analysis [20]. RV type $C$ has been recently identified due to improvements in genome sequencing and amplification 
procedures and have been linked to more severe, influenza-like upper respiratory infections and severe lower respiratory illness in infants [21]. RVs can be further characterized based upon receptors used to enter host epithelial cells with approximately $90 \%$ of serotyped strains of RV (major group) using ICAM-1 as the receptor [22], whereas the minor group is known to exploit members of the low-density lipoprotein (LDL) receptor family [23]. The entry receptor for group C RVs has yet to be identified due to propagation difficulties in vitro.

\section{Antibody responses to rhinoviruses and neutralizing epitopes}

The icosahedral protein capsid of RVs comprises 60 copies of 4 structural proteins, the surface exposed VP1, VP2, VP3 and the buried VP4 [24]. RV-specific Abs are directed against epitopes found on the surface-exposed areas of VP1, VP2 and VP3 [25], first appearing in serum and nasal secretions 1-2 weeks following infection, peaking after 5 weeks and being maintained for over 1 year [26]. RV infections are relatively short-lived (5-7 days) and despite appearing after viral clearance, Abs are critical for protection against re-infection since defence is associated with high levels of neutralizing $\mathrm{Ab}$ both in serum and respiratory secretions [26]. In general, neutralizing Abs to RV are highly serotype-specific $[18,19]$ but Abs persisting from prior encounters with other RV serotypes may cross-react with closely related RV serotypes and sometimes can cross-neutralize [9]. The importance of functional $\mathrm{Ab}$ responses in controlling RV infections has been recently demonstrated in patients with hypogammaglobulinaemia where, despite adequate intravenous immunoglobulin (IVIg) therapy, repeated and persistent RV infections [27] and significantly increased duration of RV shedding [28] have been documented, suggesting an important role for secretory $\operatorname{Ig} \mathrm{A}$ in the control of RV infections.

Numerous RV-specific murine monoclonal Abs have been generated [29-32] and rabbits and guinea pigs have been used to raise polyclonal antisera [33-36], which have aided in the identification of neutralization epitopes on the RV capsid and information on the basis of RV neutralization by Abs [25,29,37]. Structural studies showing monoclonal antibodies bound to RV indicate that effective neutralizing activity depends on $\mathrm{Ab}$ binding that both blocks virus-receptor interaction and stabilizes the virus capsid preventing uncoating and release of virus nucleic acid [10,38,39].

Structural [24], mutagenesis [37] and murine monoclonal Ab studies of major group RV14 and minor group RV2 [25,34] identified two neutralizing immunogenic sites (NIm-1a and NIm-1b) on VP1 that are located north of a depression on the capsid surface known as the canyon and two further neutralizing sites, NIm-2 on VP2 and NIm-3 on VP3 that are positioned to the south of the canyon. Analogous NIms presumably exist on numerous RV serotypes, however each NIm forms a protrusion from the virus surface and not surprisingly, these polypeptide loops are the most variable regions of the VP sequences amongst serotypes and are discontinuous epitopes, going some way to explain the high level of serotype specificity and poor cross protective abilities of neutralizing Abs.

Recent studies have revealed that immunization of rabbits with recombinant VP1 generates antisera with broad cross-serotype neutralizing properties [13] and VP1 is the dominant target of Abs in both humans [12] and mice [11] following RV infection. VP1 is the central and most external of the RV capsid proteins, contains receptor binding sites for both the major and minor group RV [40], and has a high degree of amino acid identity within both type A and B RV serotypes [41,42]. VP1 may therefore be a good target for therapeutic or prophylactic $\mathrm{Ab}$ intervention for RV infections.

\section{Prophylactic antibodies for rhinoviruses}

Several potential novel strategies for neutralization of RVs by Abs are possible. These include aggregation of virions, destabilization/stabilization of virion structure, inhibition of attachment and entry of the virus into target cells by mucosal IgA or receptor blocking IgG, and binding to nascent virions to block their release from the cell surface [43]. By combining modern antibody selection techniques (phage display, B-cell immortalization and single B-cell cloning), alternative Ab scaffolds such as single chain $\mathrm{Abs}(\mathrm{scFv})$ or lamprey [44] and camelid Abs [45] with new functional assay formats it may be possible to identify antibodies that target one or more aspects of the RV life cycle. However, due to sequence heterogeneity of RV serotypes, a single pan-serotype neutralizing $\mathrm{Ab}$ may be extremely difficult to isolate. This could potentially be addressed by identifying several Abs with considerable breadth of cross-reactive neutralization abilities and creating an Ab cocktail. A further complication for RVs is that the aforementioned NIms are largely serotype specific and that highly conserved capsid epitopes are not normally surface exposed and therefore unavailable for conventional $\mathrm{Ab}$ binding. Nevertheless, sequence conservation is found at the $\mathrm{N}$ terminus of the buried capsid protein VP4, which is transiently exposed at the surface in a process known as capsid breathing [5], and polyclonal Abs to this region are cross-serotype protective in vitro [14]. Such rare Abs may be worth further investigation as potential prophylactics, as are those Abs with the ability to interact with the conserved residues found deep in the capsid canyon - the site of ICAM-1 binding for major group RVs. However, the further potential for receptor blocking Abs of minor group RVs is complicated by the fact that the LDL receptor site is a heterogeneous 
surface exposed dome formed by the interaction of VP1 subunits, whilst the capsid site and entry receptor for the $\mathrm{RV}$ type $\mathrm{C}$ group remains unknown. An approach that may circumvent these complications is to use Abs that bind to the entry receptors, thereby blocking access of RVs. Targeting the minor and major group entry receptor has been investigated $[46,47]$ with an anti-ICAM-1 Ab approach recently described to inhibit $\mathrm{RV}$ infection in vivo [48]. One could envisage strategies where a cocktail of Abs targeting ICAM-1, LDL receptor and the RV type $\mathrm{C}$ receptor when identified, could have prophylactic possibilities.

Thus, the need is for novel identification and screening systems to isolate Abs with prophylactic or therapeutic potential. The recent development of a small animal model of RV infection [49] has improved investigations into potential RV therapeutic interventions and recently we have characterized the $\mathrm{Ab}$ responses in mice infected with RV and shown strong IgG responses to VP1 and that cross-serotype in vitro virus neutralization was generated [11]. Compared to studies in humans, this immunologically-naive model allows for simpler analyses of $\mathrm{Ab}$ responses without interference from Abs produced from previous encounters with RVs and may simplify the identification of novel potential prophylactic monoclonal Abs to RV through the use of mice transgenic for human immunoglobulin genes [50]. Despite the challenges associated with isolation of novel human monoclonal Abs to RV, one should not overlook the potential of harnessing the power of the human $\mathrm{Ab}$ response, which according to Wilson and Andrews [51] is 'a rich source of highly specific, neutralising and self tolerant therapeutic reagents'. Methods for isolating human monoclonal Abs such as phage display, B-cell immortalization and single B-cell cloning are now commonly used and when coupled with high throughput screening and downstream validation approaches, may identify rare Abs with prophylactic potential for RVs.

An important consideration for potential prophylactic Abs is what the most effective isotype that provides site-specific effector function and stability in vivo is. Secretory IgA is the most likely candidate for protection of mucosal surfaces of the upper respiratory tract, where RV infections are most frequent but their halflife in vivo is relatively short. However, one should not exclude the potential importance of the IgG isotype in protection of the lungs from RV infection. In particular, infants and those with lung disease (asthma, chronic obstructive pulmonary disease and cystic fibrosis) are more susceptible to lung infections by RVs whereas healthy adults may suffer more frequently from upper respiratory tract 'colds'. Thus as the burden of disease in these lung conditions is high, it seems likely then that combination approaches of localized IgA and systemic
IgG, depending upon the recipient, may be necessary for optimal protection of $\mathrm{RV}$ infections by prophylactic Abs.

\section{Conclusions and future}

The major challenge facing therapeutic approaches to $\mathrm{RV}$ infections is the extreme heterogeneity and continued identification/evolution of new species. A prophylactic $\mathrm{Ab}$ approach may require combinations of serotype-specific monoclonal Abs, unconventional Abs or the application of bi-specific Abs where two different Fab arms interact in a cross-serotype manner synergistically. The immediate challenge is to attempt to identify pan-serotype neutralizing monoclonal Abs, to identify the receptor for type C RVs and to investigate alternative $\mathrm{Ab}$ scaffolds or formats such as IgA and $\mathrm{scFv}$ or the application of unconventional Abs used by camels and lampreys that allow improved efficacy. Finally, the delivery, location and stability for optimal performance of such Abs requires attention to identify what approach is best suited to combat these ubiquitous human pathogens. Systemic application of IgG may not be applicable to protect the upper respiratory tract, thus nasal administration of engineered secretory IgA in the form of a spray or mist may be of benefit. Fortunately, because RV diseases are seasonal [52] and $\mathrm{Ab}$ therapies have long duration pharmacokinetics, one could imagine that several applications over one winter period when exposure is predicted to be higher could afford almost complete yearly coverage. The cost of development and application of these approaches will be considerable but when taking into account the economic cost to society of RV infections in healthy subjects due to lost productivity, absenteeism from school or work and unnecessary doctor appointments, there may be significant benefits from the approaches outlined above. Benefits are likely to be even greater in those with lung diseases caused by these infections and in patients with hypogammaglobulinaemia where IVIg therapy is not sufficient.

\section{Acknowledgements}

This work was supported in part by a Chair from Asthma UK (CH11SJ to SLJ), MRC Centre Grant G1000758, ERC FP7 Advanced grant 233015 (to SLJ), Predicta FP7 Collaborative Project grant 260895 and the Wellcome Trust sponsored Centre for Respiratory Infection.

\section{Disclosure statement}

The authors declare no competing interests. 


\section{References}

1. Schroeder HW, Jr., Cavacini L. Structure and function of immunoglobulins. J Allergy Clin Immunol 2010; 125 Suppl 2:S41-S52.

2. Köhler G, Milstein C. Continuous cultures of fused cells secreting antibody of predefined specificity. Nature 1975; 256:495-497.

3. Buss NA, Henderson SJ, McFarlane M, Shenton JM, de Haan L. Monoclonal antibody therapeutics: history and future. Curr Opin Pharmacol 2012; 12:615-622.

4. Cooper MD, Herrin BR. How did our complex immune system evolve? Nat Rev Immunol 2010; 10:2-3.

5. Lewis JK, Bothner B, Smith TJ, Siuzdak G. Antiviral agent blocks breathing of the common cold virus. Proc Natl Acad Sci U S A 1998; 95:6774-6778.

6. Marlin SD, Staunton DE, Springer TA, Stratowa C, Sommergruber W, Merluzzi VJ. A soluble form of intercellular adhesion molecule-1 inhibits rhinovirus infection. Nature 1990; 344:70-72.

7. Rollinger JM, Schmidtke M. The human rhinovirus: humanpathological impact, mechanisms of antirhinoviral agents, and strategies for their discovery. Med Res Rev 2011; 31:42-92.

8. Perkins JC, Tucker DN, Knope HL, et al. Evidence for protective effect of an inactivated rhinovirus vaccine administered by the nasal route. Am J Epidemiol 1969; 90:319-326.

9. Fox JP. Is a rhinovirus vaccine possible? Am J Epidemiol 1976; 103:345-354.

10. Smith TJ, Chase ES, Schmidt TJ, Olson NH, Baker TS. Neutralizing antibody to human rhinovirus 14 penetrates the receptor-binding canyon. Nature 1996; 383:350-354.

11. McLean GR, Walton RP, Shetty S, et al. Rhinovirus infections and immunisation induce cross-serotype reactive antibodies to VP1. Antiviral Res 2012; 95:193-201.

12. Niespodziana K, Napora K, Cabauatan C, et al. Misdirected antibody responses against an N-terminal epitope on human rhinovirus VP1 as explanation for recurrent RV infections. FASEB J 2012; 26:1001-1008.

13. Edlmayr J, Niespodziana K, Popow-Kraupp T, et al. Antibodies induced with recombinant VP1 from human rhinovirus exhibit cross-neutralisation. Eur Respir J 2011; 37:44-52.

14. Katpally U, Fu TM, Freed DC, Casimiro DR, Smith TJ. Antibodies to the buried N terminus of rhinovirus VP4 exhibit cross-serotypic neutralization. J Virol 2009; 83:7040-7048.

15. Greenberg SB. Rhinovirus and coronavirus infections. Semin Respir Crit Care Med 2007; 28:182-192.

16. Johnston SL, Pattemore PK, Sanderson G, et al. Community study of role of viral infections in exacerbations of asthma in 9-11 year old children. BMJ $1995 ; 310: 1225-1229$.

17. Rhinoviruses: a numbering system. Nature 1967; 213:761762.

18. Conant RM, Hamparian VV. Rhinoviruses: basis for a numbering system. 1 . HeLa cells for propagationand serologic procedures. J Immunol 1968; 100:107-113.

19. Conant RM, Hamparian VV. Rhinoviruses: basis for a numbering system. II. Serologic characterization of prototype strains. J Immunol 1968; 100:114-119.

20. Palmenberg AC, Spiro D, Kuzmickas R, et al. Sequencing and analyses of all known human rhinovirus genomes reveal structure and evolution. Science 2009; 324:55-59.

21. Lee WM, Kiesner C, Pappas T, et al. A diverse group of previously unrecognized human rhinoviruses are common causes of respiratory illnesses in infants. PLOS ONE 2007; 2:e966.

22. Greve JM, Davis G, Meyer AM, et al. The major human rhinovirus receptor is ICAM-1. Cell 1989; 56:839-847.
23. Hofer F, Gruenberger M, Kowalski H, et al. Members of the low density lipoprotein receptor family mediate cell entry of a minor-group common cold virus. Proc Natl Acad Sci U S A 1994; 91:1839-1842.

24. Rossmann MG, Arnold E, Erickson JW, et al. Structure of a human common cold virus and functional relationship to other picornaviruses. Nature 1985; 317:145-153.

25. Carey BS, Barclay WS, Russell SM, Tyrrell DA. The specificity of antibodies induced by infection with rhinovirus type 2. J Med Virol 1992; 36:251-258.

26. Barclay WS, al-Nakib W, Higgins PG, Tyrrell DA. The time course of the humoral immune response to rhinovirus infection. Epidemiol Infect 1989; 103:659-669.

27. Kainulainen L, Vuorinen T, Rantakokko-Jalava K, Osterback R, Ruuskanen O. Recurrent and persistent respiratory tract viral infections in patients with primary hypogammaglobulinaemia. J Allergy Clin Immunol 2010; 126:120-126.

28. Peltola V, Waris M, Kainulainen L, Kero J, Ruuskanen O. Virus shedding after human rhinovirus infection in children, adults and patients with hypogammaglobulinaemia. Clin Microbiol Infect 2013; 19:E322-E327.

29. Sherry B, Mosser AG, Colonno RJ, Rueckert RR. Use of monoclonal antibodies to identify four neutralization immunogens on a common cold picornavirus, human rhinovirus 14. J Virol 1986; 57:246-257.

30. Appleyard G, Russell SM, Clarke BE, Speller SA, Trowbridge M, Vadolas J. Neutralization epitopes of human rhinovirus type 2.J Gen Virol 1990; 71:1275-1282.

31. Barnett PV, Rowlands DJ, Parry NR. Characterization of monoclonal antibodies raised against a synthetic peptide capable of inducing a neutralizing response to human rhinovirus type 2. J Gen Virol 1993; 74:1295-1302.

32. Skern T, Neubauer C, Frasel L, et al. A neutralizing epitope on human rhinovirus type 2 includes amino acid residues between 153 and 164 of virus capsid protein VP2. J Gen Virol 1987; 68:315-323.

33. Cooney MK, Fox JP, Kenny GE. Antigenic groupings of 90 rhinovirus serotypes. Infect Immun 1982; 37:642-647.

34. Hastings GZ, Speller SA, Francis MJ. Neutralizing antibodies to human rhinovirus produced in laboratory animals and humans that recognize a linear sequence from VP2. J Gen Virol 1990; 71:3055-3059.

35. McCray J, Werner G. Different rhinovirus serotypes neutralized by antipeptide antibodies. Nature 1987; 329:736-738.

36. Francis MJ, Hastings GZ, Sangar DV, et al. A synthetic peptide which elicits neutralizing antibody against human rhinovirus type 2. J Gen Virol 1987; 68:2687-2691.

37. Sherry B, Rueckert R. Evidence for at least two dominant neutralization antigens on human rhinovirus 14.J Virol 1985; 53:137-143.

38. Smith TJ, Olson NH, Cheng RH, Chase ES, Baker TS. Structure of a human rhinovirus-bivalently bound antibody complex: implications for viral neutralization and antibody flexibility. Proc Natl Acad Sci U S A 1993; 90:7015-7018.

39. Tormo J, Blaas D, Parry NR, Rowlands D, Stuart D, Fita I. Crystal structure of a human rhinovirus neutralizing antibody complexed with a peptide derived from viral capsid protein VP2. EMBO J 1994; 13:2247-2256.

40. Vlasak M, Blomqvist S, Hovi T, Hewat E, Blaas D. Sequence and structure of human rhinoviruses reveal the basis of receptor discrimination. J Virol 2003; 77:6923-6930.

41. Laine P, Blomqvist S, Savolainen C, Andries K, Hovi T. Alignment of capsid protein VP1 sequences of all human rhinovirus prototype strains: conserved motifs and functional domains. J Gen Virol 2006; 87:129-138.

42. Ledford RM, Patel NR, Demenczuk TM, et al. VP1 sequencing of all human rhinovirus serotypes: insights into genus phylogeny and susceptibility to antiviral capsidbinding compounds. I Virol 2004; 78:3663-3674.

43. Reading SA, Dimmock NJ. Neutralization of animal virus infectivity by antibody. Arch Virol 2007; 152:1047-1059. 
44. Herrin BR, Alder MN, Roux KH, et al. Structure and specificity of lamprey monoclonal antibodies. Proc Nat Acad Sci U S A 2008; 105:2040-2045.

45. Harmsen MM, De Haard HJ. Properties, production, and applications of camelid single-domain antibody fragments. Appl Microbiol Biotechnol 2007; 77:13-22.

46. Hodits RA, Nimpf J, Pfistermueller DM, et al. An antibody fragment from a phage display library competes for ligand binding to the low density lipoprotein receptor family and inhibits rhinovirus infection. J Biol Chem 1995 270:24078-24085.

47. Charles CH, Luo GX, Kohlstaedt LA, et al. Prevention of human rhinovirus infection by multivalent fab molecules directed against ICAM-1. Antimicrob Agents Chemother 2003; 47:1503-1508.

48. Traub, S, Nikonova A, Carruthers A, et al. An anti-human ICAM-1 antibody inhibits rhinoviral exacerbation of lung inflammation. PLoS Pathogens 2013; in press.
49. Bartlett NW, Walton RP, Edwards MR, et al. Mouse models of rhinovirus-induced disease and exacerbation of allergic airway inflammation. Nat Med 2008; 14:199-204.

50. Jakobovits A, Amado RG, Yang X, Roskos L, Schwab G. From XenoMouse technology to panitumumab, the first fully human antibody product from transgenic mice. Nat Biotechnol 2007; 25:1134-1143.

51. Wilson PC, Andrews SF. Tools to therapeutically harness the human antibody response. Nat Rev Immunol 2012; 12:709-719.

52. Johnston SL, Pattemore PK, Sanderson G, et al. The relationship between upper respiratory infections and hospital admissions for asthma: a time-trend analysis. Am J Respir Crit Care Med 1996; 154:654-660. 